\title{
Researching Masculinity and Men's Sexual Health in Bangladesh: Methodological Reflections
}

\author{
Kamrul Hasan \\ Centre for Social Research in Health, UNSW Sydney, Australia
}

DOI: https://doi.org/10.18778/1733-8077.17.4.03

Keywords:

Sexuality;

Masculinities;

Reflexivity; Sexual

Health; Qualitative

Research; Bangladesh

\begin{abstract}
Sex and sexuality are deemed "sensitive" issues in relatively conservative, predominantly Muslim countries. Men's sex and sexualities research within such cultural contexts confronts certain challenges and raises important methodological issues. This paper reflects on some of the methodological issues and challenges encountered when carrying out a study in Bangladesh. It reports on a male researcher's qualitative study of men's sexual health and masculinity in Bangladesh, a predominantly Muslim country where sexuality is largely constituted as a taboo subject. The researcher faced challenges in gaining access and in discussing sex and sexuality issues in interview settings. Moreover, the interview context emerged as a site for expressing, negotiating, challenging men and masculinities. Drawing upon experiences in navigating the "field" in Bangladesh, some of the useful ways of researching "sensitive" issues such as sex, sexuality, and masculinity within these settings are suggested, highlighting what works when researching men's sexual health and masculinity.
\end{abstract}

Md Kamrul Hasan is an Adjunct Research Fellow at the Bangladesh Institute of Social Research Trust (BISRT) and a staff member at Western Sydney University, Australia. He held positions at BRAC University in Bangladesh and at Chiang Mai University, Thailand. He holds a Ph.D. from UNSW Sydney. His research interests encompass masculinities and men's health, disasters, disability, ICT and healthcare, international development, and gender.

email address: mhas089@aucklanduni.ac.nz

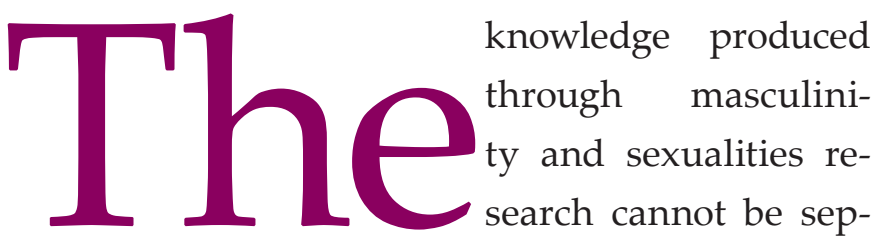

arated, or considered in isolation, from the social reality actively co-produced both by the researcher and research participants. For this reason, since the 1980s, there has been increasing emphasis on the researcher's reflexivity (Kulick and Wilson 1995). Anthropological literature on sexuality research has shown that researchers' positionality, as well as 
their sexual desire, plays a vital role in the production of knowledge (Kulick 1995).

Social research in general, and research on sex and sexualities in particular, is constituted as "sensitive" (Elam and Fenton 2003). Although "sexuality is everywhere" (Deleuze and Guattari 1988:293), and sexualities research is necessary and "intrinsically interesting" (Fisher 1989:144), the study of sexualities is considered a taboo subject (Sharpe and Pinto 2006). There are dangers, risks, and shame associated with sexualities research (McCormack 2014). Researchers reported issues and difficulties with respect to representations of research interviews (Roulston 2016). In addition, they expressed fear of misrepresentation of sexuality research in the media (Irvine 2002), difficulty in getting through ethics committees (Allen et al. 2014), and publishing in top-ranked journals (McCormack 2014). Some researchers spoke of causing public embarrassment by studying sex and sexuality in relatively conservative countries (Roudsari et al. 2013).

Researching sex and sexuality carries implications not only for researchers but also for research participants. The researcher is seen as the "other" (McCormack 2014). Therefore, participation and engagement in such research may produce discomfort for both and may also trigger public reactions. Researchers suggest that moral panics pervade sexuality research or the implementation of sexual health education in the context of schools involving children and/or young people (Irvine 2002; Sikes 2008; Allen et al. 2014). Poole, Giles, and Moore (2004) indicate that researching sex and sexuality can have negative consequences for both professional and personal lives. The personal and professional lives of sexualities researchers are affected because friends, family members, colleagues, religious groups, strangers, and the public react in specific ways when they learn about such research. They tend to express titillation, outrage, ridicule, and stigma towards the researcher, who may also be discriminated against (Fisher 1989).

Discomfort and negative experiences may be more strongly experienced by researchers in conservative, predominantly Muslim countries where public discussion of sex and sexuality triggers more intense responses among religious groups, politicians, and the public. Sex and sexuality are contentious issues in Muslim countries such as Iran (Tabatabaie 2015a), Bangladesh (Siddiqi 2011; Anam 2014; Ahmed et al. 2020), and Indonesia (Bennett and Davies 2014), where these topics generate debates and complex responses from a wide range of groups. Similarly, writing about women's sexuality in countries where there is a substantial number of Muslim populations is challenging and is often seen as threatening to religion, the state, and society (Beck et al. 2005; Ahmed-Ghosh 2012). As Khan (2006:90) put it,

In almost all Muslim countries, people are still reserved when it comes to sex. It is still very much a taboo topic, something to be spoken about behind closed doors. Sex is hushed and curtained off to the bedroom, and speaking about it is considered a sin, accredits a loose character, and many other such remarks prevailing in Muslim society.

Religion is a powerful social institution shaping sexual practices, as well as sexuality research. It establishes the boundaries of acceptable sexuality, forbidding particular sexual orientation, practices while allowing certain other sexual norms, practices, and beliefs (Khan 2006; Hunt and Jung 2009; Dialmy 2010). Islam, for instance, strongly regulates pre-marital and extra-marital sex. In Iran, for exam- 
ple, a high percentage (about $73 \%$ ) of female college students viewed pre-marital heterosexual relations as unacceptable (Farahani and Cleland 2015; Tabatabaie 2015a; 2015b). "Islam...is often perceived as rigid in controlling all aspects of its believers' lives, and intolerant of any expressions of sexuality outside of the context of heterosexual marriage" (Yip 2009:2).

Sexuality is an important element of masculinity. Over the last 40 years, the critical study of men and masculinities has emerged as a distinctive field of academic inquiry and a matter of policy concern (Haywood and Mac an Ghaill 2003:128-132; Connell 2005:xii). Concurrently, research on the critical study of sex and sexuality, too, has emerged as a distinctive field of research, as opposed to traditional, quantitative sex research focusing on sexual dysfunctions (Dowsett 2015). It is important to recognize that the study of sex, sexuality, and sexual health raises important methodological issues. For instance, researching sexual behavior raises concerns about the accuracy of self-reported sexual behaviors (Schroder, Carey, and Vanable 2003). Likewise, studying men and masculinities raises methodological concerns about the methods used (Hearn 2013; Pini and Pease 2013). However, there is little methodological reflection on studying sex, sexuality, masculinity, and men's health, especially in settings such as Bangladesh.

Compared to the spectacular growth of the field of men and masculinities and critical sexualities studies, methodological literature focused on these topics is sparse and underdeveloped. What Haywood and Mac an Ghaill (2003:121) observed still appears to be true, "In fact, sustained methodological discussions of masculinity have yet to take place." As Pini and Pease (2013:1) similarly wrote:
Notwithstanding the growth of this scholarship [studies of men and masculinities], we have been struck by the relative lack of interrogation of the epistemologies and methodologies involved in the study of men and masculinities...masculinity scholars have generally not problematized the methodologies they have chosen to research men's lives.

By contrast, feminism has been characterized by a relatively well-developed methodological literature called feminist methodologies.

Bangladesh is a predominantly Muslim, largely patriarchal, and conservative country located in South Asia. The taboo attached to sex, heteronormativity, and cultural norms prohibiting pre-marital sex spread in society renders the sexual largely invisible. Despite a taboo assigned to sex and sexualities, rapid population growth, concerns about women's reproductive health, and the fear of HIV and AIDS have opened up opportunities for researching sex and sexuality in Bangladesh (Khan 1997; Khan et al. 2005; Muna 2005; Imtiaz 2012). Although sex and sexuality are seen as taboo subjects, pre-marital and extra-marital sex occurs secretly often transgressing the acceptable norms of sexuality (Siddiqi 2011) and masculinity (Hasan, Aggleton, and Persson 2019). Although some methodological literature concerning studying sex and masculinity exists in other contexts (Pini and Pease 2013; Allen et al. 2014; McCormack 2014), hardly any published work focused exclusively on researching men's sexual health and masculinities in Bangladeshi contexts.

To address the gap in the literature outlined above, this paper seeks to provide an overview of some of the critical methodological issues that unfolded when studying men and masculinities in relation 
to men's sexual health in Bangladesh. In the light of the reflections presented, the article offers some fresh thoughts about how best to methodologically approach masculinities and sexual health in an Islamic context. To that end, I begin with a brief note on the research study undertaken. Next, some of the key methodological issues and problems are discussed before offering some suggestions with respect to studying men's sexual health and masculinity in conservative cultural settings such as Bangladesh.

\section{Men's Sexual Health and Masculinities Study}

I completed a research study at the University of New South Wales (UNSW Sydney), exploring the implications of generational masculinities for men's sexual health in Bangladesh. A variety of influences in my educational, professional, and personal background drew me to the study of men, masculinities, and sexual health. My interest in pursuing a doctoral study in a health-related field developed through my engagement with health, development, human rights, social justice, and gender issues over a decade as a student, researcher, development worker, and teacher. My interest in men's sexual health was also shaped by my growing up as a heterosexually-attracted Muslim man in Bangladesh, which required me constantly to negotiate, adhere to, and resist different forms of masculinity.

I learned that little research in South Asia to date has focused on men as gendered subjects, on masculinities, or men's sexual health. To address this gap in the literature, my research has been examining the implications of cultural gender ideologies and enactments of masculinity for men's sexual health in Bangladesh. The research applied semi-structured interviews with 34 Bangladeshi men representing three generations. My study sought to examine the implications of multiple and performative masculinities for men's sexual health. I drew on Raewyn Connell's (2005) theory of multiple masculinities and Judith Butler's (1990) theory of gender performativity. These theories stress that masculinities are context-bound, multiple, emergent, and are subject to change across time and space.

Using a cross-sectional study design, I conducted the research in three Bangladeshi cities with men belonging to three social generations. The selection of participants was informed by Mannheim's (1952) work on social generations. For this study, the three groups of men comprised the "war generation" (pre-1971), the "post-war generation" (post1971), and the "generation of the new millennium" (post-2010s). I utilized semi-structured interviews with a total of 34 men; 10 men from the older social generation, 11 men from the middle social generation, and 13 men from the younger social generation. Details about this study were published previously (Hasan, Aggleton, and Persson 2017). Most older generation men were illiterate, married or widowed, and ranged in age from 56 to 75 years. Most of them were retired and some were engaged in informal economic activities such as rickshaw pulling and driving. Most middle generation men were educated to the secondary level, were married, and were employed in van driving, small trading, garments factory work, and office assistance. Two of them held university degrees and were involved in teaching. In contrast, almost all younger generation men were university students and aged between 18 to 27 years. Younger generation men were unmarried, but most had romantic relationships. 
At the time of interviewing, these men lived in three separate Bangladeshi cities such as Dhaka, Chittagong (now named Chattogram), and Gazipur. Dhaka is a megacity and the capital city, which is about 500 years old. This historic city is a center of commerce, trade, education, administration with a high concentration of ready-made garments (RMG) factories. Chittagong is also a historic city located close to the Bay of Bengal. Bangladesh's second-largest city Chittagong is the country's busiest seaport. The other location, Gazipur, was until recently a town, but now has become a city. It is also an important center of business, RMG factories, and educational institutions.

After obtaining ethics approval from UNSW Sydney, I conducted semi-structured interviews face-toface with each man. Men's accounts were captured by using a digital audio recorder. A semi-structured interview guide was used to facilitate the interviews. The semi-structured nature of the interviews allowed for flexibility in asking questions that were not in the guide. Each interview was conducted for about one hour. In a few cases, when there was confusion about information that an interviewee provided, they were asked for clarification on a second meeting or over the phone. I regularly recorded field notes, methodological issues, and challenges, observations, and analytical points during my stay in the study locations.

My research raised a number of methodological and practical issues. As discussed below, gaining access to research participants, getting them to talk openly about sexuality matters in the context of the interviews, and the emergence of the interview context as a site for negotiating masculinity were some of the issues that required innovative thinking and strategies. In addition, my social generational lo- cation, educational, class, and professional background influenced the study.

\section{Researching Men's Sexual Health and Masculinity: Methodological Reflections}

\section{Negotiating Access, Encountering Gatekeepers}

Given that sex and sexuality are perceived as taboo subjects in Bangladesh due to the shame and stigma assigned to these, entering the field and gaining access to participants was not always easy. A few potential participants declined to take part in the research. Often reasons for non-participation could not be known. Most participants who did not participate either did not want to disclose their sexual practices or perhaps had engaged in pre-marital or extra-marital sex, which is mainly framed as "bad" in Bangladesh. Being an insider as a Bangladeshi and having lived in the study sites for a total period of five and a half months, I learned that this was the case. I had an opportunity to informally chat with a number of men during the fieldwork and learned about their life, male culture, and their sexual practices. Some had had sexual relationships outside marriage, a practice that was largely viewed as immoral, anti-religious, and anti-social.

To gain access, I had to use several different recruitment strategies. An advertisement for recruiting research participants was initially circulated through several non-government organizations (NGOs) and higher education institutions in all three research sites. The NGOs work closely with local communities to improve the health of local populations. The higher education institutions were the University of Chittagong in Chittagong and BRAC University located in Dhaka. 
Some men had initially expressed an interest to participate, but after learning more about the research topic, they later declined to do so. In most cases, reasons for non-participation were not known. Then, however, I came to know from third parties and sometimes through my connection with male networks of potential participants (some of whom had earlier declined to participate) that one of the main reasons for some men's non-participation was their involvement in pre-marital or extra-marital sex, which constitutes a violation of social, religious, and sexual norms in Bangladesh. A Muslim married man in his mid-thirties, who declined to participate, later revealed during informal conversations that he had had sex with numerous partners. He considered himself handsome and popular among women. He spoke of going to official and sex tours with his female Chinese boss to Cox's Bazaar, a South-Western beach town that attracts many tourists. His male friends suspected that he had often gone out of his locality to have paid sex with sex workers. Besides this, shyness, the cultural taboo ascribed to sex, and concerns over privacy may have prevented men from participating.

Overall, gaining access to and recruiting middle and younger generation men was the easiest because of their and my generational location. Men belonging to these generations tended to be more economically active, more educated, and more mobile than their older counterparts, which enabled them to respond to the advertisement. In addition, since most of the middle social generation men were of my age, they considered me as a friend with whom sexuality matters can easily be discussed.

During my fieldwork, I encountered some influential gatekeepers while attempting to recruit older generation men. The recruitment of men belonging to the older generation proved particularly tricky. I initially tried to recruit men of this social generation through specialized institutions, including homes for the elderly located in Dhaka and Gazipur. While most of the NGOs and universities I contacted assisted in circulating the advertisements, two old-age homes in which I had wished to recruit older men did not want to assist in any way with the recruitment. I realized that these organizations might have viewed the topic as "too sensitive" to talk about. I, therefore, needed to slightly change the recruitment strategy based on feedback received from local researchers. I used a snowball sampling technique later to recruit older generation men.

\section{Discussing Sex and Sexuality in Interviews}

Although the semi-structured interview method used in this study was well suited to the study of social generational masculinities and sexualities, it must be recognized that no method of inquiry is entirely perfect for grasping the densely complex worlds where gender and sexuality collide (Plummer 2010). While semi-structured interviews helped provide rich accounts, given the sensitivity of the research topic, perhaps many aspects of men's sexual practices could not be known about through this study. A small number of potential participants refused to participate in this study because, perhaps, they did not want to discuss sexual health issues, while some who had had pre-marital sex were afraid of the disclosure of such information.

In addition, non-participation by some middle and younger social generation men who had initially expressed an interest may also have influenced the findings. During interviews with men of all social generations, there were occasions when participants avoided answering questions relating to sexual 
practices. Perception of being seen as sexually different or "deviant" had an impact on research conversations. Similarly, some of the questions asked about non-normative sexual relations appeared to produce discomfort for some research participants and me. However, older social generation men provided only the briefest of answers to these kinds of questions, saying that they knew nothing about same-sex sexuality and claiming that they had never engaged in same-sex sexual relations.

Some participants did not answer some questions relating to sexual practices. For example, a heterosexual man refused to disclose where sex with his girlfriend had taken place, as this was an instance of pre-marital sex, which was not socially acceptable and had occurred secretly. A 23 years old university student similarly refused to answer a question about his views on engagement in pre-marital sex and Islam. This younger generation man, who identified as a Muslim, reported during the interview that he had engaged in pre-marital sex. Following his disclosure, I probed him about his views on the disapproval of engagement in pre-marital sex in Islam. Being slightly offended by the follow-up probing question, he requested me not to ask such a sensitive question again during the interview.

In a predominantly Muslim and conservative social setting such as that where this research was undertaken, both questions and responses, as well as research conversations, were underpinned by the dominant cultural discourses of sexuality, gender, and religion. Although many men were not aware of their gender/sexual subjectivities, their accounts revealed that most were largely heterosexist. Because of this, informants may have censored themselves while answering or discussing aspects of themselves as men and especially their sexual prac- tices. Men of all three social generations talked very little about non-partnered sexual practices such as masturbation. As I shared some of the same cultural sensibilities as the participants did in this study, there were occasions where I, too, censored myself by not asking "too sensitive" questions about these and related matters.

It is important to note that research interviews are a site for social interaction in which people use symbols to communicate meanings. As interactionist sociologists ${ }^{1}$ have long argued, actors engage in meaning-making, meaning-giving, and impression management across a multiplicity of social settings (Goffman 1956). In this respect, the interview context is no different. Some of the participants in this study may have engaged in impression management by attempting to valorize the more performative aspects of masculinity (e.g., marital sexual prowess), while sometimes avoiding certain topics (pre-marital sexual encounters). Khairul, for instance, talked in detail about how well he lived up to the ideals of masculinity in the Bangladeshi context by being a good provider for his family and by taking care of his old mother.

In brief, questioning and responses in this study were underpinned by dominant normative discourses about sexuality. Participants often made strongly heteronormative, heterosexist assumptions, which I did not dare to challenge. Sometimes questions that were deemed as "too sensitive" by men were avoided, resulting in little or no discussion around same-sex relations with older men, and the nature of sexual activity with men from all gen-

\footnotetext{
${ }^{1}$ Interactionist sociologists emphasize the importance that symbols such as words, facial expressions, and gestures play in social interaction. They consider actors as meaning-giving beings. They suggest that behaviors and identities are profoundly shaped by social interaction.
} 
erations. Some questions may have produced a degree of discomfort because they open up what is "normative" and usually not talked about.

\section{The Influences of Researcher's Background on Fieldwork}

The study indicated that researchers' and participants' age, religious beliefs, gender, heteronormative assumptions, cultural beliefs, social rank, education level, and power relations all shaped how the field unfolded. This, ultimately, influenced what was known through the research about men's enactments of masculinities and their sexual practices. Participants seemed to perceive me as a respectable, educated man with knowledge about the study topic and, therefore, they at times inquired whether their responses were right. This signals that they wanted to respond in ways that pleased me, on the one hand, and, on the other hand, they did not want to come across as ignorant or unaware. This suggests that the hierarchical research relationships influenced men's narratives in this study and the knowledge produced through such a study, indicating the social locatedness of knowledge about sexual practices and men's sexual health.

Effective qualitative interviewing is underpinned by the relationship between the researcher and research participants, and the nature of this relationship may influence the data that are co-produced in the interview (Connolly and Reilly 2007 as cited in Cowburn 2013:186). For example, the gender of the researcher can influence the direction, tone, and content of the research conversation (Cowburn 2013:187), with male participants being more likely than women to express more misogynistic, sexist, and homophobic attitudes to a male researcher than to a female researcher (Coates 2003:197 as cit- ed in Cowburn 2013:187). As South Asian culture is largely heteronormative with strong homosocial bonds between men, study participants sometimes expressed sexist and homophobic views. I did not dare to challenge many of these ideas, foreseeing possible repercussions such as embarrassment, fear, or even threat. At the same time, and paradoxically, the same homosocial bond helped build a stronger rapport between some participants and me. Since a higher degree of shame is culturally associated with cross-sex conversation in Bangladesh, it would have been more difficult for a female researcher to conduct research on male sexual health with men. Thus, the homosocial bonds formed during the fieldwork worked to the advantage of the research.

Existing social hierarchies were also reproduced during the interviews. These hierarchies link closely to differences in age, education, prior knowledge about the study topic, power, and so forth. Their presence can give rise to somewhat incompatible understandings of the topics discussed. Sometimes participants and I understood different things in terms of notions of masculinity, sexual practices, and sexual health. Some participants tended to consider masculinity and men as the same concepts, while I brought with me a different view. Many older and middle social generation men seemed to understand sexual health narrowly as sexual success through penetration or as not having worries about semen loss, while my view of sexual health was much broader. The theoretical framework that I employed throughout the study enabled me to develop a progressively more nuanced understanding of the topics discussed during the interviews. Possible differences in the knowledge of key terms between participants and me need to be taken into consideration while interpreting the findings and conclusions. 
Given my generational location within which the middle generation men of this study were situated, older men may have seen me as a son, middle generation men as a member of their peer group or bhai (brother), and younger generation men may have viewed me as an "older" and respectable educated person. For this reason, my relationship with the older generation men and younger generation men was more hierarchical than the middle generation men. These research relationships tended to influence what was said and not said in the interviews. For example, because of the narrower age gap, middle generation men tended to disclose more than their older counterparts, especially about extra-marital sexual practices. In contrast, some younger generation men felt discomfort in discussing certain topics such as pre-marital sexual relationships.

\section{The "Field" as a Site for Expressing Masculinities}

In the Bangladeshi context, research indicated that being sexually successful is an important dimension of hegemonic masculinity (Hasan et al. 2017), which is an honorable form of masculinity (Connell 2005). The dominant notions of masculinity were reproduced and articulated by research participants in the context of the interviews. "Interviews can themselves be a site for producing, or challenging, men and masculinities" (Hearn 2013:28). In the case of this study, too, the field emerged as a site in which participants expressed sexualized masculinities through their narratives. As being a "good" Muslim man represents a form of hegemonic masculinity, participants often have to engage in "impression management" and "face-work" (Goffman 1956) to protect aspects of honorable masculinity embodied in being a "good" Muslim man who did not engage in pre-marital or extra-marital sex. Akkas (70 years old, chef) repeated in the interview that he had never had pre-marital or extra-marital sex, thus expressing an honorable aspect of Muslim masculinities. By representing himself as sexually "pure," Akkas seemed to engage in impression management.

At times, in line with the dominant discourses of masculinity that emphasize men's sexual strength, some men valorized and appeared to exaggerate their narratives of sexual prowess, which they constituted as a manly characteristic. An older Mozammel (72 years old, retired) proudly narrated a story of his wedding night when he had had six sex sessions. Thus, some participants such as Mozammel often tended to valorize their narratives of sexual potency and sexual achievement while trying to conceal accounts of sexual impotence. Concurrently, a married man in his $40 \mathrm{~s}$ appeared to be in a dilemma about participating in the study because after being unemployed for years, he might have realized that his masculinity was at stake. He was living in Gazipur and was away from his family living in another town. Foreseeing that an interview that required information about one's employment and sexual life could pose a challenge to his masculinity, he did not participate in the study in the end, although he had initially expressed willingness to partake. Thus, non-participation was a means of defending his sense of manhood. Therefore, both the valorization of sexual performance and non-participation were ways of enacting and defending masculine honor or ways of impression management.

In contrast to Mozammel, other men such as Mazid (35 years old, factory worker) expressed a "subordinated masculinity" (i.e., forms of masculinity that are culturally de-valued) (Connell 2005). He attempted to hide narratives of sexual impotence that might undermine his sense of manhood. He explained that he had encountered sexual health problems, such as not being able to have sex with his wife for a long time, and, therefore, he felt that he was not a real man. For 
Mazid, this feeling of being less of a man was exacerbated by his low income and his employment in lowpaid informal sector economic activities.

Indeed, I'm now not a real man. First, my wife complained against me once. She asked me to be with her for more time [during sex]...[And the second wife] hasn't been finding enough moja [sexual pleasure] for the last two years. She's now saying, "Be with me for a longer time." But, I couldn't give her this [moja]. From this point of view, I've totally failed. Another failure is that I'm not able to provide my child and wife with enough subsistence...I'm from all sides nobody. I'm not a real man if one looks at my economic situation, my work, and my wife's demands. I'm not a real man from all these perspectives. I can say I'm not a full man.

Thus, men's narratives suggested that the interview context may emerge as a site for the production, reproduction, and (re)negotiation of masculinity.

Although most men from the older generation subscribed to the dominant patterns of traditional masculinity, some men from the younger generation tended to resist older forms of masculinity. For instance, Nahian (27 years old, researcher) said he was not bothered about whether he was seen as masculine or feminine. He said that he had had sex with numerous men and women, which is a challenge to traditional Bangladeshi and Islamic masculinity.

\section{What Worked? Research Strategies}

To address some of the issues and problems, I used several strategies in carrying out the research. Since two homes for older people had declined to assist in the recruitment and considering the high illiteracy rate among men of this generation, snowball sampling had to be adapted. I requested several middle social generation men to circulate the advertisement and to spread it through word of mouth to potential older social generation research participants. Next, I requested each older generation man interviewed to verbally inform other potential older social generation participants about the research. One older social generation man from Chittagong, who initially verbally consented to participate in the study, withdrew on the very eve of the interview. With a low literacy level and little understanding of the research process, he became skeptical of the signing of the Participant Information Statement.

Building rapport and trust was an important first step in gaining access and facilitating open communication and dialogue throughout the interviews (Dean et al. 2012:913). I attempted to build rapport with participants by interacting with them, and by talking informally to break the ice before the interview commenced. After greeting, I disclosed information about myself, such as my place of origin, education, work, family, and the purpose of the interview. Some asked me about the sources of funding for the present research. These early conversations helped build a degree of trust and confidence, as was reflected in their willingness to participate in the study. However, I later realized that conducting interviews for a second time with all interviewees could have built stronger rapport and trust. This would have facilitated a greater level of disclosure from the participants.

Later, I paid careful attention to the ordering of questions in the interview guide. Following Patton's (1990) advice, to encourage disclosure and reduce discomfort during the interview, I asked sensitive questions relating to sexuality and sexual health only after a discussion of other topic areas. I probed participants about their romantic and sexual relationships and sexual practices. In this way, the interviews grad- 
ually moved on to more sensitive topics. These latter types of questions were posed to elicit information about sexual partners, the nature of sexual activities, the formation of sexual relationships, marriage, sex in and/or outside of marriage, condom use, and so on.

Another key interviewing strategy that worked was asking indirect questions to probe into sensitive issues. Occasionally, indirect or "projective questions" were used to elicit information on topics that were perceived as more sensitive than others. This type of questioning, which enquires into the attitudes and practices of "other people," may offer insight into participants' attitudes and practices, which they might not be prepared to speak about directly (Liamputtong 2013:57). Given the heteronormative, Islamic cultural context in which the research was conducted, I found it difficult to ask direct questions about whether participants had had any same-sex relations. Heteronormativity refers to the beliefs and discourses that render heterosexuality as "normal." Indirect questions proved helpful in eliciting useful information about same-sex relations from some of the middle and younger social generation men, without producing major discomfort or embarrassment. Overall, it was noticeable that participants grew more comfortable and more interested in the research as interviewing progressed. Towards the end and/or after the interviews, some participants told me that they had disclosed more than they had expected they would. As I had gained participants' trust and confidence, several men told me that they had found it easy to tell me the "truth" or disclosed more than what they otherwise might do.

Indirect questioning techniques and open-ended questions were used to reduce discomfort. In contrast, discussion of same-sex attraction/sexuality was difficult with older men. The indirect questioning technique was somewhat useful in this regard. Instead of asking directly about men's engagement in same-sex relationships, I asked whether they knew about it or what they thought about it. This type of projective question elicited an intended answer without disrupting the relationship or producing discomfort for the participants and me. The following conversation from an interview with an older generation man named Kashem (75 years old, retired, Muslim, Gazipur) illustrates this point.

I: In your time, did you hear about sex between men? Kashem: No, I didn't do it, neither did I hear about it. I heard that some people do it. Suppose, he's a man, I'm also a man, doing it with him is of no use. I heard men of this era do it. Allah [God] knows.

Additionally, being of the same sex as informants was an advantage in the sense that cross-sex conversation on "sensitive" topics such as sexuality is not common in the strongly homosocial Bangladeshi context. Despite the taboo attached to public discussion of sex in the country, the topic is discussed in all-male homosocial settings, and this created a favorable situation during the interview.

\section{Conclusion}

In this paper, I have sought to present a reflective account of a study on men's sexual health and masculinity conducted in a predominantly Muslim country where the dominant discourses of gender, religion, sexuality, and culture influenced how the research was conducted. The broader cultural and social context, as well as the interview situation, ultimately influenced the knowledge produced through such a study. The study raised a set of methodological challenges including gaining access; discussing sexuality matters in interviews; the influence of the researcher's background on the research process; and participants' engagement in "impression management" (Goffman 1956). 
Although there might be methodological challenges, it is not impossible to conduct research on sex, sexuality, and masculinity in conservative, Islamic settings. However, careful planning, innovative strategies, and preparation are required when studying sex, sexuality, and masculinity within such contexts. An awareness of the socio-cultural framing of sexuality and masculinities is of pivotal importance when conducting research on these topics. Researchers may need to prepare themselves to address methodological challenges as efficiently as possible. This paper alerts us to some of the potential methodological issues that might arise when researching sex, sexual health, and masculinity in conservative, Islamic contexts. In addition, knowledge produced through specific methods and within such contexts needs to be considered when interpreting research findings.

That said, the reflexive accounts provided in this paper offer some insights and teach some useful lessons about conducting research in men's sexual health and masculinities in conservative settings. It is advisable to build a strong rapport with research participants well before the fieldwork starts. Furthermore, to strengthen rapport and build trust, it would be useful to conduct interviews for a second time. Particular attention needs to be paid to the ordering of interview questions with more "sensitive" questions being asked towards the end of the interview after participants are eased into the research conversations. When it is difficult or impossible to ask "too sensitive" questions, projective or indirect interview questions might prove useful. These questions can generate valuable insights about the study problem while not offending the research participants or the researcher concerned.

In addition to indirect questioning, creating homosocial bonds when researching masculinity and sexuality in conservative settings would prove effective. The foregoing discussion has indicated that men belonging to the middle social generation to which I belonged as a researcher and as a man helped build a stronger connection and thus encouraged a higher level of disclosures from men of this specific generation. This means that the more homogenous the researcher and research participants are, the more trustworthy the relationship would be, and this would ultimately make it easier to conduct research on sensitive topics in conservative cultural settings such as Bangladesh.

Finally, it is also important to critically reflect on and interrogate the knowledge on sex, sexuality, and masculinity that are generated through research because responses are underpinned by the relationship between the researcher and research participants, and by methodologies used. The social hierarchy and cultural discourses also shape what is said and not said in interviews. Therefore, reflexivity is crucially important in the studies of men, masculinity, and sexual health. Future researchers on masculinities and sexual health in countries such as Bangladesh need to reflect on their methodologies more critically.

\section{Acknowledgments}

The author would like to sincerely thank his doctoral supervisors, Emeritus Scientia Professor Peter Aggleton and Dr. Asha Persson, Adjunct Senior Lecturer at UNSW Sydney. He would also like to thank the anonymous reviewers for their valuable comments on an earlier version of the manuscript. The author gratefully acknowledges the support received from various Bangladeshi higher academic institutions and non-government organizations. Funding for the research was received from the Faculty of Arts and Social Sciences, UNSW Sydney. 


\section{References}

Ahmed, Rushdia et al. 2020. "Challenges and Strategies in Conducting Sexual and Reproductive Health Research among Rohingya Refugees in Cox's Bazar, Bangladesh." Conflict and Health 14(1):1-8.

Ahmed-Ghosh, Huma. 2012. "Introduction: Lesbians, Sexuality, and Islam." Journal of Lesbian Studies 16(4):377-380.

Allen, Louisa et al. 2014. "Who's Afraid of Sex at School? The Politics of Researching Culture, Religion and Sexuality at School." International Journal of Research \& Method in Education 37(1):31-43.

Anam, Md Mujibul. 2014. "When Sexuality Is in a Research Topic! The Methodological Challenges in Sexuality and Street Healing Research in Bangladesh." The Oriental Anthropologist 14(1):27-40.

Beck, Andrew et al. 2005. "'We Don't Really Have Cause to Discuss These Things, They Don't Affect Us': A Collaborative Model for Developing Culturally Appropriate Sexual Health Services with the Bangladeshi Community of Tower Hamlets." Sexually Transmitted Infections 81(2):158-162.

Bennett, Linda Rae and Sharyn Graham Davies. 2014. Sex and Sexualities in Contemporary Indonesia: Sexual Politics, Health, Diversity and Representations. Abingdon: Routledge.

Butler, Judith. 1990. Gender Trouble and the Subversion of Identity. New York: Routledge.

Connell, Raewyn. 2005. Masculinities. Sydney: Allen \& Unwin.

Cowburn, Malcolm. 2013. "Men Researching Violent Men: Epistemologies, Ethics and Emotions in Qualitative Research." Pp. 183-196 in Men, Masculinities and Methodologies, edited by B. Pini and B. Pease. Hampshire: Palgrave Macmillan.

Dean, Judith et al. 2012. "Hidden Yet Visible: Methodological Challenges Researching Sexual Health in Sudanese Refugee Communities." Culture, Health \& Sexuality 14(8):911-924.

Deleuze, Gilles and Félix Guattari. 1988. A Thousand Plateaus. London: Athlone.

Dialmy, Abdessamad. 2010. "Sexuality and Islam." The European Journal of Contraception E Reproductive Health Care 15(3):160168.
Dowsett, Gary W. 2015. "The Price of Pulchritude, the Cost of Concupiscence: How to Have Sex in Late Modernity." Culture, Health E Sexuality 17(1):5-19. doi: 10.1080/13691058.2014.959563.

Elam, Gillian and Kevin A. Fenton. 2003. "Researching Sensitive Issues and Ethnicity: Lessons from Sexual Health." Ethnicity and Health 8(1):15-27.

Farahani, Farideh Khalajabadi and John Cleland. 2015. “Perceived Norms of Premarital Heterosexual Relationships and Sexuality among Female College Students in Tehran." Culture, Health \& Sexuality 17(6):700-717.

Fisher, Terri D. 1989. "Confessions of a Closet Sex Researcher." The Journal of Sex Research 26(1):144-147.

Goffman, Erving. 1956. The Presentation of Self in Everyday Life. Edinburg: University of Edinburg.

Hasan, Kamrul, Peter Aggleton, and Asha Persson. 2017. "The Makings of a Man: Social Generational Masculinities in Bangladesh." Journal of Gender Studies 27(3):347-61. doi: 10.1080/09589236.2017.1388773.

Hasan, Kamrul, Peter Aggleton, and Asha Persson. 2019. “Sexual Practices and Sexual Health among Three Generations of Men in Bangladesh: Exploring Gender- and Sexuality-Assemblages." Sexuality \& Culture 23:475-93. doi: 10.1007/s12119-018-9566-7.

Haywood, Chris and Máirtín Mac an Ghaill. 2003. Men and Masculinities: Theory, Research and Social Practice. Buckingham, Philadelphia: Open University Press.

Hearn, Jeff. 2013. "Methods and Methodologies in Critical Studies on Men and Masculinities." Pp. 26-38 in Men, Masculinities and Methodologies, edited by B. Pini and B. Pease. Hampshire: Palgrave Macmillan.

Hunt, Mary E. and Patricia Beattie Jung. 2009. "“Good Sex' and Religion: A Feminist Overview." Journal of Sex Research 46(23):156-167.

Imtiaz, Sana. 2012. Young Men in a Colourful City: Masculinity, Young Men's Sexual Practices, and HIVIAIDS in Dhaka, Bangladesh. Ph.D. thesis, University of Amsterdam, Amsterdam.

Irvine, Janice M. 2002. Talk about Sex: The Battles over Sex Education in the United States. Berkeley, CA: University of California Press. 
Khan, Muhammad A. 2006. Sex and Sexuality in Islam. Lahore: Nashriyat.

Khan, Sharful. 1997. Sex, Secrecy and Shamefulness: Developing a Sexual Health Response to the Needs of Males Who Have Sex with Males in Dhaka, Bangladesh. Dhaka: Naz Foundation International.

Khan, Sharful et al. 2005. "Men Who Have Sex with Men's Sexual Relations with Women in Bangladesh." Culture, Health $\mathcal{E}$ Sexuality 7(2):159-169.

Kulick, Don. 1995. "Introduction. The Sexual Life of Anthropologists: Erotic Subjectivity and Ethnographic Work." Pp. 1321 in Taboo, edited by D. Kulick and M. Wilson. London: Routledge.

Kulick, Don and Margaret Willson, eds. 1995. Taboo. Sex, Identity and Erotic Subjectivity in Anthropological Fieldwork. London, New York: Routledge.

Liamputtong, Pranee. 2013. Qualitative Research Methods. South Melbourne: Oxford University Press.

Mannheim, Karl. 1952. “The Problem of Generations." Pp. 276320 in Essays on the Sociology of Knowledge, edited by P. Kecskemeti. London: Routledge \& Kegan Paul.

McCormack, Mark. 2014. "Is Sexuality Research 'Dirty Work?'” Sexualities 17(5-6):674-676.

Muna, Lazeena. 2005. Romance and Pleasure: Understanding the Sexual Conduct of Young People in Dhaka in the Era of HIV and AIDS. Dhaka: University Press Limited.

Patton, Michael. 1990. Qualitative Evaluation and Research Methods. Newbury Park, CA: Sage.

Pini, Barbara and Bob Pease. 2013. "Gendering Methodologies in the Study of Men and Masculinities." Pp. 1-25 in Men, Masculinities and Methodologies, edited by B. Pini and B. Pease. Hampshire: Palgrave Macmillan.
Plummer, Ken. 2010. “Generational Sexualities, Subterranean Traditions, and the Hauntings of the Sexual World: Some Preliminary Remarks." Symbolic Interaction 33(2):163-190.

Poole, Hayley, David C. Giles, and Karen Moore. 2004. “Researching Sexuality and Sexual Issues: Implications for the Researcher?" Sexual and Relationship Therapy 19(1):79-86.

Roudsari, Robab Latifnejad et al. 2013. "Socio-Cultural Challenges to Sexual Health Education for Female Adolescents in Iran." Iranian Journal of Reproductive Medicine 11(2):101-110.

Roulston, Kathryn. 2016. "Issues Involved in Methodological Analyses of Research Interviews." Qualitative Research Journal 16(1):68-79.

Schroder, Kerstin E. E., Michael P. Carey, and Peter A. Vanable. 2003. "Methodological Challenges in Research on Sexual Risk Behavior: II. Accuracy of Self-Reports." Annals of Behavioral Medicine 26(2):104-123. doi: 10.1207/s15324796abm2602_03.

Sharpe, Jenny and Samantha Pinto. 2006. "The Sweetest Taboo: Studies of Caribbean Sexualities. A Review Essay." Signs: Journal of Women in Culture and Society 32(1):247-274.

Siddiqi, Dina M. 2011. "Sexuality, Rights and Personhood: Tensions in a Transnational World." BMC International Health and Human Rights 11(3):S5.

Sikes, Pat. 2008. "Forward." Pp. vii-xii in From Teacher to Lover: Sex Scandals in the Classroom. New York: Peter Lang.

Tabatabaie, Alireza. 2015a. "Constructing the Ideal Muslim Sexual Subject: Problematics of School-Based Sex Education in Iran." Sex Education 15(2):204-216.

Tabatabaie, Alireza. 2015b. “Childhood and Adolescent Sexuality, Islam, and Problematics of Sex Education: A Call for Re-Examination." Sex Education 15(3):276-288.

Yip, Andrew Kam-Tuck. 2009. "Islam and Sexuality: Orthodoxy and Contestations." Contemporary Islam 3(1):1-5.

\section{Citation}

Hasan, Kamrul. 2021. “Researching Masculinity and Men's Sexual Health in Bangladesh: Methodological Reflections.” Qualitative Sociology Review 17(4):44-57. Retrieved Month, Year (http://www.qualitativesociologyreview.org/ENG/archive_eng.php). DOI: https://doi.org/10.18778/1733-8077.17.4.03 